J. Jasiński, G. Walczak, M. Lubas, M. Szota

Politechnika Częstochowska, Wydział Inżynierii Materiałowej, Procesowej i Fizyki Stosowanej, Instytut Inżynierii Materiałowej, Zakład Biomateriałów i Inżynierii Powierzchni, Częstochowa, Poland

\title{
ANALIZA EKONOMICZNA PROCESU UTLENIANIA TYTANU W ZLOŻY FLUIDALNYM
}

\begin{abstract}
STRESZCZENIE
Własności tytanu takie jak: duża wytrzymałość w stosunku do masy, odporność na korozje sprawiają że jest on powszechnie stosowany w różnych gałęziach przemysłu. Można wymienić dla przykładu przemysł lotniczy, kosmiczny, motoryzacyjny. Oprócz wymienionych cech, tytan ma także dużą biokompatybilność $\mathrm{z}$ organizmem ludzkim. Fakt ten, $\mathrm{w}$ połączeniu $\mathrm{z}$ własnościami wytrzymałościowymi sprawiają, iż jego stopy maja wiele zastosowań biomedycznych. Aby polepszyć jego biozgodność i odporność na korozję, wytwarza się na jego powierzchni warstwę tlenków, której grubość wynosi $10-20 \mu \mathrm{m}$. Jedna z metod uzyskania warstwy utlenionej jest obróbka cieplno-chemiczna W złożu fluidalnym. Właściwe przeprowadzenie takiego procesu technologicznego powoduje poprawę wymienionych własności.

W niniejszym artykule zostanie przedstawiony schemat stanowiska do utleniania tytanu w złożu fluidalnym. Zaprezentowany zostanie przykładowy przebieg obróbki cieplno-chemicznej, który poddany będzie rozważaniu w aspekcie ekonomicznym. Analiza procesu wykaże wpływ parametrów technologicznych, na zużycie mediów niezbędnych w tym procesie.
\end{abstract}

Stowa kluczowe: złoże fluidalne, ekonomia, obróbka cieplna

\section{WSTĘP}

Obróbka cieplno-chemiczna w złożu fluidalnym częściowo zbliżona jest do obróbki cieplnej w kąpieli a częściowo do obróbki w zwykłym piecu grzewczym. Wsad zostaje umieszczony $\mathrm{w}$ materiale fluidyzujaccym (rys. 1.). Jest to materiał ziarnisty o odpowiednio dobranej granulacji, umieszczony w retorcie pieca. Doprowadzenie gazu technicznego do wnętrza retorty, pod odpowiednim ciśnieniem tak, aby utrzymać parametry przepływu na zadanym poziomie, powoduje, że złoże fluidalne zachowuje się podobnie jak ciecz. W tym przypadku ośrodek fluidyzujący przejął rolę kąpieli. Medium fluidyzacyjne jest doprowadzone poprzez instalacje ciśnieniową, a źródłem gazów technicznych są odpowiednio podłączone butle gazowe. W przypadku utleniania stosuje się sprężone powietrze, poddane filtracji. W celu zwiększenia udziału tlenu w medium fluidyzacyjnym, można do złoża dostarczyć mieszaninę powietrza $\mathrm{z}$ tlenem. Elementy grzejne pieca, zamieniają energie elektryczną na energie cieplną, konieczną do nagrzania złoża fluidalnego i wsadu. 
Proces obróbki cieplnej jest przeprowadzany w pełni automatycznie, dzięki zastosowaniu różnego rodzaju sterowników PLC, mikroprocesorowych, które kontrolują przebieg procesu. Pomiar temperatury w piecu, jest realizowany za pomoca układu termopar, połączonych bezpośrednio z układem sterowania, który w czasie rzeczywistym dokonuje pomiarów temperatur. Na rysunku 1 pokazano układ dwóch termopar, $\mathrm{Tp}_{1} \mathrm{i} \mathrm{Tp}_{2}$, który pozwala uzyskać większą dokładność sterowania, oraz w pewien zakresie ograniczyć wpływ bezwładności cieplnej pieca. Sterownik PLC, traktuje sygnał $\mathrm{z}$ termopar jako sprzężenie zwrotne $\mathrm{w}$ układzie sterowania regulatorem mocy. Zadany sygnał sterujący, na układ regulatora mocy, wpływa na ilość dostarczonej energii elektrycznej, co przekłada się na ilość energii cieplnej dostarczanej do złoża fluidalnego. W ten sposób odbywa się kontrola i nadzór nad poprawnym przebiegiem charakterystyki temperaturowej procesu cieplnego.

Sterownik PLC, kontroluje przepływ powietrza oraz odpowiednie proporcje jego mieszaniny $\mathrm{z}$ gazami technicznymi. Pamiętać należy, że przepływ medium fluidyzacyjnego, powinien być równy zadanemu i jednostajny w trakcie trwania całego procesu cieplnego, co zapobiega tzw. spiekaniu się materiału ziarnistego. Źle dobrany poziom przepływu gazu, powoduje powstawanie kanalikowania lub tłokowania złoża fluidyzującego.

Podwyższona temperatura oraz obecność fluidyzującego materiału ziarnistego, wokół obrabianego detalu, powodują zwiększenie dynamiki dyfuzji atomów tlenu z powietrza wgłąb obrabianego detalu. Efektywne utlenianie warstwy tytanu przeprowadza się $\mathrm{w}$ granicach $500-700^{\circ} \mathrm{C}$, przy czym górne wartości temperatur powodują znaczny rozrost ziarna, a dolne zwiększenie czasu trwania obróbki cieplnochemicznej.

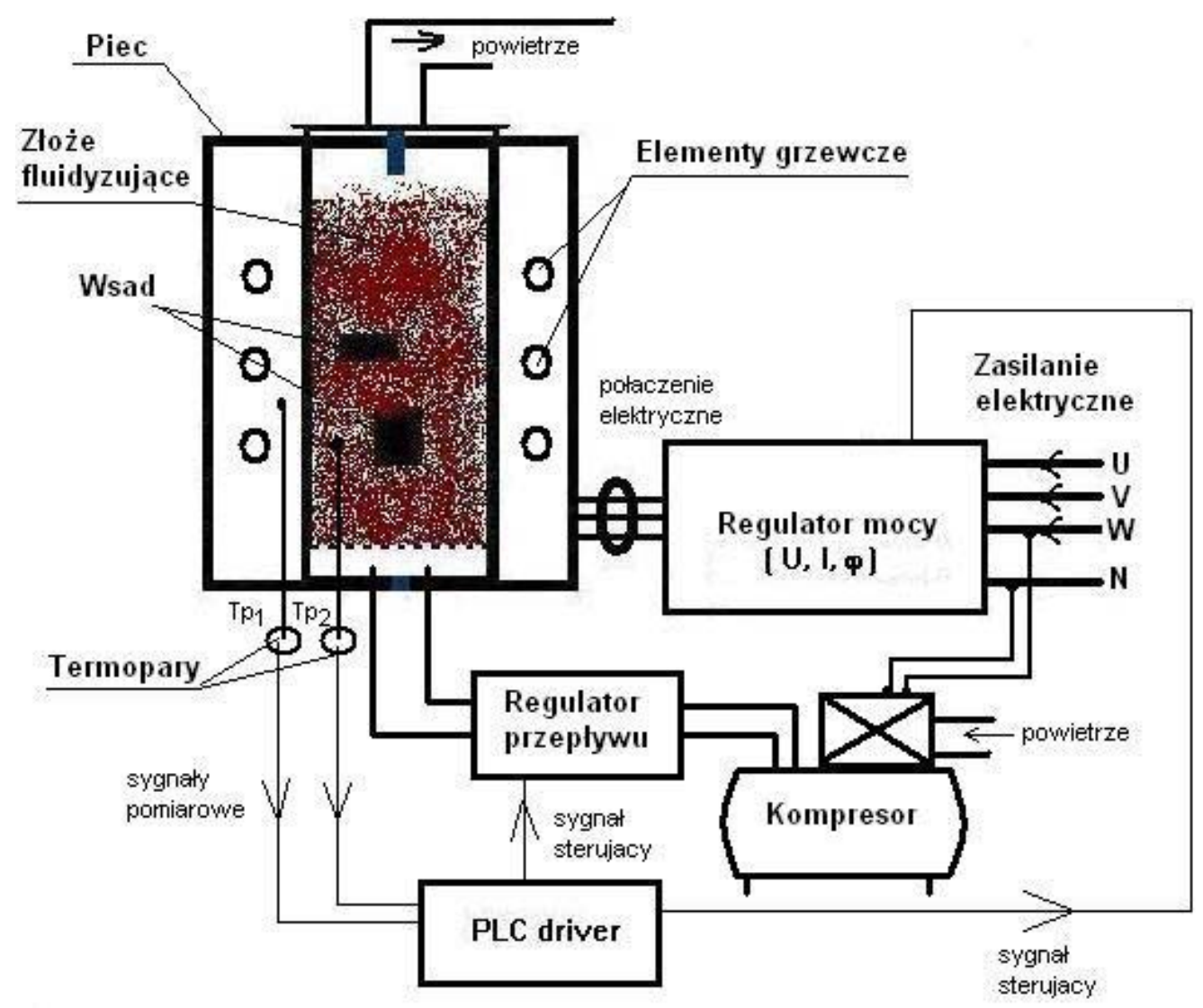

Rys. 1. Schemat systemu do fluidalnej obróbki cieplnej i cieplno-chemicznej 


\section{ANALIZA EKONOMICZNA UTLENIANIA}

Przeanalizowane zostanie zużycie mediów energetycznych, niezbędnych do przeprowadzenia opisywanej wcześniej, obróbki cieplno-chemicznej. Z przedstawionej charakterystyki procesu cieplno-chemicznego wynika, że głównymi odbiorami energii elektrycznej jest regulator mocy wraz piecem oraz układ dystrybucji gazów technicznych wraz z kompresorem. Na rys.1. pominięto zasilanie sterownika PLC, gdyż moc znamionowa tego elementu w stosunku do pieca i kompresora jest niewielka.

Najwięcej energii elektrycznej zostanie pobrane przez piec grzewczy. Elektryczne piece do obróbki cieplnej mają moce rzędu 10 do około $50 \mathrm{~kW}$, a czas obróbki cieplno-chemicznej to kilka, -kilkadziesiąt godzin. Moc znamionowa pieca, opisywanego w tym artykule wynosi 40kW. Moc kompresora to wartość około 1 do $4 \mathrm{~kW}$, a więc znacznie mniej niż $\mathrm{w}$ przypadku pieca, stąd i pobór energii będzie dużo mniejszy. Moc znamionowa sprężarki powietrza stosowanej $\mathrm{w}$ przedstawionym układzie instalacji fluidalnej, wynosi 2,2kW. Moc układu sterowania jest rzędu kilkudziesięciu watów. Przepływ gazów (powietrza) jest sterowany przez zawory elektrostatyczne małej mocy. Zatem w dalszych rozważaniach zostały pominięte

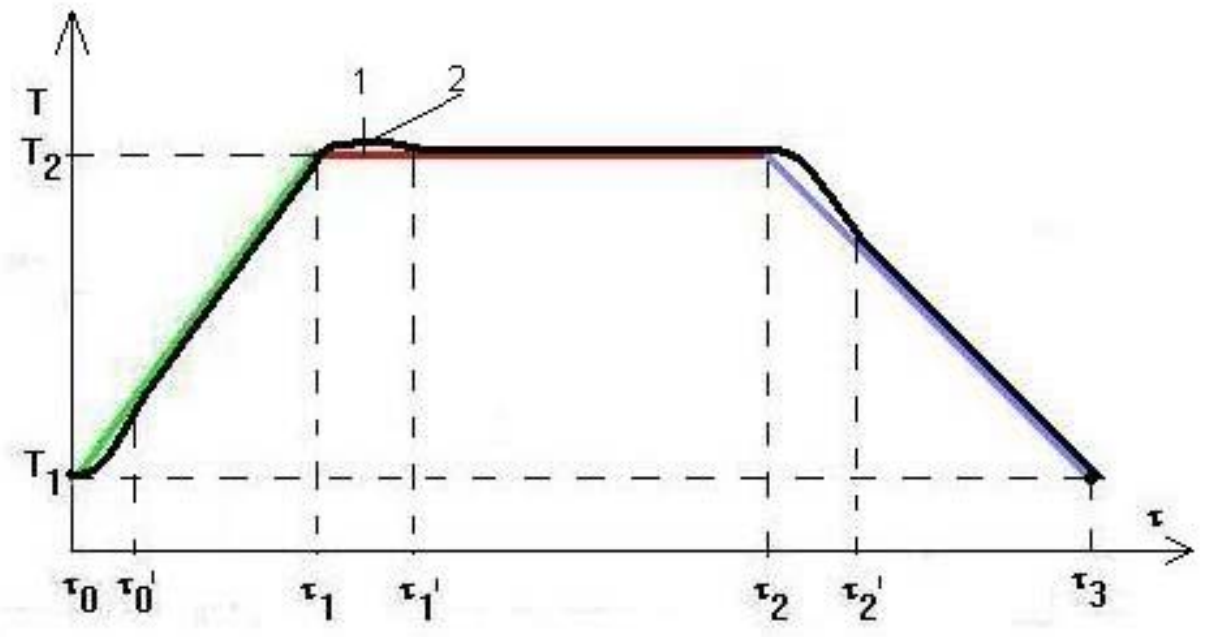

Rys. 2. Przykładowy przebieg charakterystyki temperaturowej: 1- idealnej, 2-rzeczywistej

te odbiorniki mocy, ze względu na znikomy wkład w sumaryczną energię elektryczną potrzebną na przeprowadzenie procesu cieplno-chemiczną. Dalszej analizie poddany zostanie pobór mocy przez piec grzewczy i kompresor.

Aby rozważyć przebieg poboru energii elektrycznej w czasie, przeanalizujemy charakterystyki temperaturowe $\mathrm{T}=\mathrm{f}(\tau)$, pokazane na rys. 2. Charakterystyka nr. 1 odpowiada teoretycznym zmianom temperatury detalu oraz składa się ona $\mathrm{z}$ trzech prostych, odpowiadających odpowiednio zabiegowi nagrzewania, wygrzewania i chłodzenia. Przyrost temperatury jest funkcją liniową, więc teoretycznie energia elektryczna powinna być dostarczana w sposób liniowy, jednak w rzeczywistości charakterystyka ta nieco odbiega od wcześniej założonej. Dla tego przypadku zostanie przeprowadzona analiza poboru energii elektrycznej.

Z porównania charakterystyki temperaturowej i rzeczywistej wynikają pewne rozbieżności. Rozważając początek zabiegu nagrzewania ( $\tau_{0}$ do $\left.\tau_{0}{ }^{\prime}\right)$, zauważalne jest przesunięcie charakterystyk (idealnej i rzeczywistej) w czasie. W chwili początkowej 
$\tau_{0}$, piec ma temperaturę $T_{1}$ oraz rozpoczęto dostarczać energia elektryczna. Energia cieplna, powstająca $\mathrm{w}$ elementach grzejnych potrzebuje czasu, aby rozprzestrzenić się i dotrzeć do obrabianego detalu. Stąd widoczne opóźnienie czasowe. Po czasie $\tau_{0}$ ' temperatura osiąga wartość zgodną $\mathrm{z}$ zadaną teoretyczną charakterystyką temperaturową.

W końcowej części zabiegu nagrzewania zachodzi podobny efekt, z tą jednak różnica, że piec jest już nagrzany, elementy grzejne dostarczają energie cieplną, aż do $\tau_{1}$. W chwili tej następuje ograniczenie dostarczanej mocy elektrycznej, ale reakcja na zmniejszenia energii elektrycznej zachodzi z opóźnieniem.

Przykładowy przebieg charakterystyki mocy w funkcji czasu $\mathrm{P}=\mathrm{f}(\tau)$, dla pieca pokazano na rys. 3 . Zauważyć można, że $\mathrm{w}$ chwili początkowej $\tau_{0}$, układ regulacji mocy dostarcza do elementów grzejnych maksymalną moc elektryczna, jaką piec może wykorzystać. Energia ta zostanie wykorzystana na wstępne nagrzanie układu fluidyzacyjnego. Jednak po pewnej chwili następuje spadek mocy dostarczanej do $\mathrm{P}_{2}$. Jest to spowodowane tym, że temperatura wsadu jest zgodna $\mathrm{z}$ temperatura zadanej charakterystyki nagrzewania. Ponieważ przyrost temperatury jest od chwili $\tau_{0}$ ' liniowy dla rzeczywistej charakterystyki, to i także moc dostarczana w tym czasie jest liniowa na stałym poziomie.

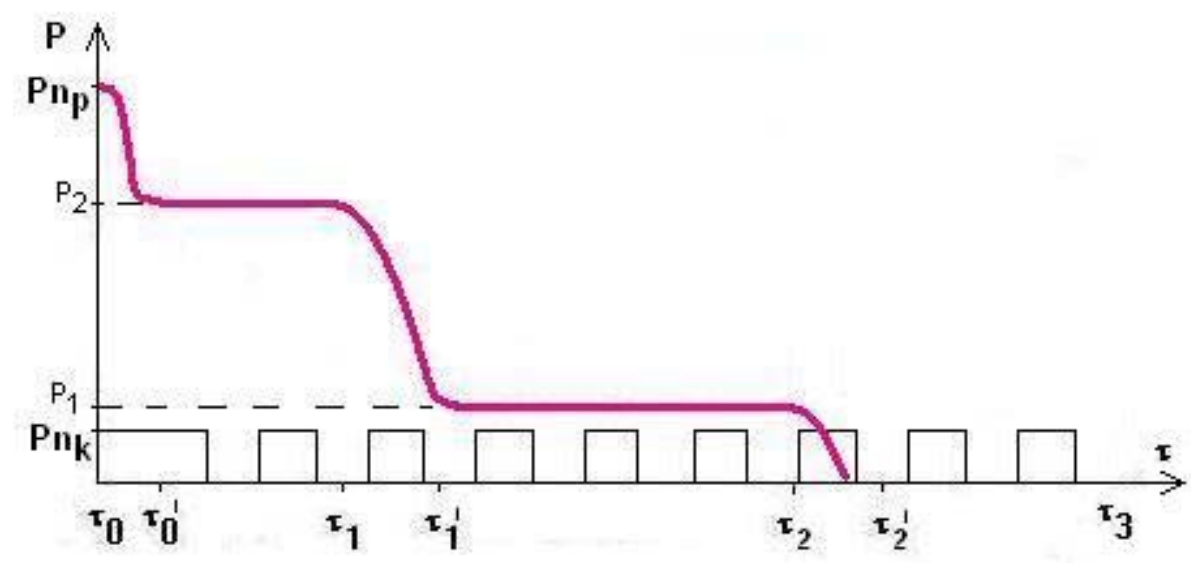

Rys. 3. Charakterystyka mocy dla pieca grzewczego $P n_{p}$ i kompresora $P n_{k}$

Gdy, w chwili czasowej $\tau_{1}$, wsad osiaga temperaturę wygrzewania, następuje zmniejszenie ilości dostarczanej mocy do wartości $P_{1}$. Od chwili $\tau_{1}$ ' do $\tau_{2}$ teoretycznie nie jest już dostarczana energia cieplna do wsadu. Pamiętając, że piec ma pewną sprawność $\eta$ ( zazwyczaj około 50-80\%), temperatura będzie obniżała się, w skutek tych strat cieplnych. Należy, więc doprowadzić dodatkową ilość energii elektrycznej, niezbędną na pokrycie tych strat, w celu zapewnienia zgodności wartości temperatury $\mathrm{z}$ charakterystyką dla zabiegu wygrzewania.

Po zakończeniu zabiegu wygrzewania, poziom dostarczanej mocy zazwyczaj spada do wartości zerowej. Standardowo w tym zabiegu chłodzenie detalu przebiega razem z piecem, bez dostarczenia energii elektrycznej do pieca. Bardzo często detal jest wyciagany z pieca i chłodzony w swobodnym powietrzu. Stąd energia pobrana $\mathrm{w}$ tym zabiegu będzie niewielka.

$\mathrm{Na}$ rys. 3. zaznaczono także przykładowy pobór mocy przez kompresor. $\mathrm{Z}$ charakterystyki wynika, że energia jest pobierana impulsowo, co jest spowodowane działaniem regulatora ciśnienia kompresora. Sprężarka kończy swoją prace, gdy 
ciśnienie w butli przekroczy pewną określoną wartość, zwykle dużo większą aniżeli potrzebną do obróbki. Stąd potrzeba stosowania regulatora przepływu powietrza, który powoduje spadek ciśnienia $\mathrm{w}$ butli kompresora. Jeśli zostanie przekroczona pewna dolna graniczna wartość, kompresor uruchamia się automatycznie (regulator ciśnienia), i dlatego też charakterystyka ta jest impulsowa.

\section{WNIOSKI}

Z analizy charakterystyk temperaturowych, dla utleniania tytanu, można poznać przebieg zapotrzebowania na moc w czasie oraz wyznaczyć ilość energii elektrycznej niezbędnej do przeprowadzenia procesu cieplno-chemicznego. Zostało pokazane zmienne zapotrzebowanie na moc, z czego wynika, że ilość energii elektrycznej pobieranej $\mathrm{w}$ procesie cieplno-chemicznym nie jest iloczynem mocy znamionowej $\mathrm{Pn}_{\mathrm{p}}$ i czasu $\tau_{3}$. Energia elektryczna pobrana przez piec grzewczy jest polem pod wykresem poboru mocy w czasie dla tego urządzenia. Podobnie będzie w przypadku kompresora, dla którego przebieg charakterystyki mocy jest impulsowy. Mnożąc sumaryczną energię elektryczna, wyznaczoną podczas badań, przez jej aktualna cenę, można poznać koszty procesu związane z poborem energii elektrycznej.

Wartość mocy $\mathrm{P}_{2}$ jest zależna od charakterystyki nagrzewania oraz od masy wsadu, co jest zgodne z rzeczywistością. Zwiększając stromość charakterystyki podczas zabiegu nagrzewania, zwiększamy wartość mocy $\mathrm{P}_{2}$, a co za tym idzie zwiększa się ilość energii elektrycznej, potrzebnej na szybsze podniesienie temperatury wsadu. W przypadku, gdy znacznie zwiększymy masę wsadu, wartość $\mathrm{P}_{2}$ musi ulec zwiększeniu, $\mathrm{w}$ przeciwnym razie szybkość narastania temperatury, $\mathrm{w}$ fazie nagrzewania, ulegnie znacznemu zmniejszeniu, co odbiega od zadanej charakterystyki temperaturowej.

Ważnym elementem wpływającym na pobór energii elektrycznej, ekonomie procesu oraz jakość obróbki cieplnej jest sterownik PLC, a właściwie algorytm regulacji zaimplementowany $\mathrm{w}$ programie tego urządzenia. Pozwala on na określenie inercji pieca grzewczego, a tym samym opóźnień zmian temperaturowych, oraz na wcześniejsze zapobieganie tym rozbieżnością. Zatem charakterystyka rzeczywista pokazana na rys. 2. będzie również zależała od algorytmu regulacji temperaturą pieca.

\section{LITERATURA}

1. Tyrkiel E.: Termodynamiczne podstawy materiałoznawstwa, Wydawnictwo Politechniki Warszawskiej, 2005.

2. Brzózka J.: Regulatory i Układy Automatyki, Wydawnictwo Mikom, 2004.

3. Barlik R., Nowak M. Układy sterowania i regulacji urządzeń energoelektronicznych, WSiP, 1998.

4. Dobrzański L. A.: Materiały inżynierskie i projektowanie materiałowe, WNT, 2006.

5. Bylica A., Sieniawski J.: Tytan i jego stopy, PWN, 1985.

6. Michałowski S., Wańkowicz K.: Termodynamika procesowa, WNT, 1999. 